\title{
KNOWLEDGE MANAGEMENT FOR PROBLEM SOLVING USING SEMISTRUCTURED CONTRADICTION MATRIX BASED ON PHYSICAL QUANTITY DESCRIPTION
}

\author{
Murakami, Tamotsu \\ University of Tokyo
}

\begin{abstract}
A Contradiction Matrix of TRIZ that classifies problems to solve as contradictions of features is an effective framework of knowledge management for problem solving. The features, however, may have a problem of completeness because they may not cover contradictions about all physical phenomena. In addition, rigidly structured Contradiction Matrix may have a problem of searchability because a relevant contradiction may not be properly searched if a recorder and a retriever describe it differently. To solve these problems, this paper proposes a semistructured contradiction matrix using not TRIZ features but physical quantities in SI unit. To enable not only exact match but also partial match in searching for relevant contradictions, dimensional similarity and qualitative value similarity of physical quantity and similarity between contradictions are defined. The proposed method is implemented as software in Python and contradictions are described in XML and stored in a semistructured matrix. From the result of similarity calculation between stored contradictions, possible effectiveness of the proposed method is confirmed.
\end{abstract}

Keywords: Knowledge management, Creativity, Computational design methods, TRIZ, Quantity dimension

Contact:

Murakami, Tamotsu

University of Tokyo

Department of Mechanical Engineering

Japan

murakami@mech.t.u-tokyo.ac.jp

Cite this article: Murakami, T. (2019) 'Knowledge Management for Problem Solving Using Semistructured Contradiction Matrix Based on Physical Quantity Description', in Proceedings of the 22nd International Conference on Engineering Design (ICED19), Delft, The Netherlands, 5-8 August 2019. DOI:10.1017/dsi.2019.204 


\section{INTRODUCTION}

A Contradiction Matrix of TRIZ (Mann, 2001) to classify problems to be solved as contradictions between 39 features is an effective framework of knowledge management for problem solving. There is a survey, however, pointing out some challenges with TRIZ such as "very structured and wordcentric, not easily adaptable to visual or intuitive thinking styles" (Ilevbare et al., 2013). Additionally, current features of TRIZ may have a limitation in completeness, i.e., the features may not be able to cover properly all possible problems to appear in the future and Contradiction Matrix may have a limitation in searchability, i.e., a person to store a contradiction and its solution in a database and a person to search for a contradiction to solve in the database may describe a same contradiction in different ways.

To solve such possible limitations of features and Contradiction Matrix of TRIZ, the author proposes a new framework of knowledge management for problem solving using physical quantities in SI unit instead of 39 features and a semistructured contradiction matrix instead of rigidly structured Contradiction Matrix. This paper reports the basic concept of the framework, the outline of data description and processing, and output examples of the implemented prototype software.

\section{TRIZ CONTRADICTION MATRIX}

\subsection{Contradiction Matrix as knowledge management framework}

In TRIZ, the original 39 features have been elaborated by analysing enormous patents so that they can characterize problems to be solved (Table 1(a)) (Mann, 2002a). Then the problem is described as a contradiction between two of the features. For example, if we want to make a portable pointing rod, it should be sufficiently long to use and sufficiently small to carry. Since the two conditions seem conflicting, it is described as a contradiction between the features " 3 . Length of moving object" and "8. Volume of stationary object". In TRIZ, such contradictions are classified in a $39 \times 39$ matrix based on 39 features named Contradiction Matrix (Mann, 2002a) (Figure 1(a)). This contradiction between features 3 and 8 is placed in the cell marked " $X$ " in Figure 1(a).

Table 1. Features to describe contradictions in TRIZ

(a) Classical 39 features

\begin{tabular}{|l|l|}
\hline 1. Weight of moving object & 2. Weight of stationary object \\
\hline 3. Length of moving object & 4. Length of stationary object \\
\hline 5. Area of moving object & 6. Area of stationary object \\
\hline 7. Volume of moving object & 8. Volume of stationary object \\
\hline 9. Speed & 10. Force \\
\hline 11. Stress or pressure & 12. Shape \\
\hline 13. Stability of the object's composition \\
\hline 14. Strength \\
\hline 15. Duration of action by a moving object \\
\hline 16. Duration of action by a stationary object \\
\hline 17. Temperature \\
\hline 18. Illumination intensity \\
\hline 19. Use of energy by moving object \\
\hline 20. Use of energy by stationary object \\
\hline 21. Power & 22. Loss of Energy \\
\hline 23. Loss of substance & 24. Loss of Information \\
\hline 25. Loss of Time & 26. Quantity of substance/the matter \\
\hline
\end{tabular}

\begin{tabular}{|l|}
\hline 27. Reliability \\
\hline 28. Measurement accuracy \\
\hline 29. Manufacturing precision \\
\hline 30. External harm affects the \\
\hline object \\
\hline $\begin{array}{l}\text { 31. Object-generated harmful } \\
\text { factors }\end{array}$ \\
\hline 32. Ease of manufacture \\
\hline 33. Ease of operation \\
\hline 34. Ease of repair \\
\hline 35. Adaptability or versatility \\
\hline 36. Device complexity \\
\hline $\begin{array}{l}\text { 37. Difficulty of detecting and } \\
\text { measuring }\end{array}$ \\
\hline 38. Extent of automation \\
\hline 39. Productivity \\
\hline
\end{tabular}

(b) Additional 11 features (50 features in total have been renumbered)

\begin{tabular}{|l|}
\hline 11. Amount of information \\
\hline 24. Function efficiency \\
\hline 29. Noise \\
\hline 30. Harmful emission \\
\hline
\end{tabular}

\begin{tabular}{|l|}
\hline 33. Compatibility/connectivity \\
\hline 37. Security \\
\hline 38. Safety/vulnerability \\
\hline 39. Aesthetics/appearance \\
\hline
\end{tabular}

\begin{tabular}{|l|}
\hline 46. Control complexity \\
\hline 47. Positive intangible Factors \\
\hline 48. Negative intangible Factors \\
\hline
\end{tabular}




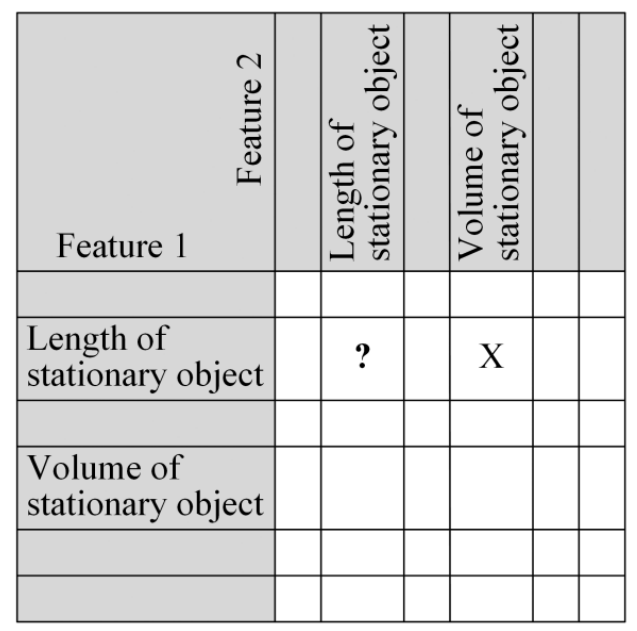

(a) TRIZ Contradiction Matrix

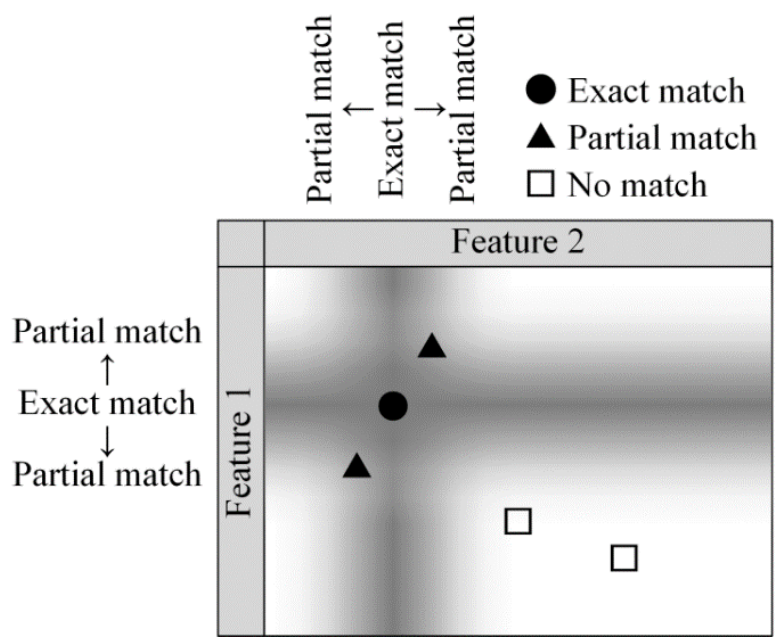

(b) Proposed semistructured matrix

Figure 1. Contradiction matrix

The problem of portable pointing rod can be solved as a stretchable bar using a nested structure or an optical pointer using small laser oscillator, and TRIZ classifies such solutions as 40 Inventive Principles (Mann, 2002a). For example, a nested structure solution is classified in "7. Nesting (Matrioshka)" and an optical solution is classified in "28. Replacement of mechanical system". In TRIZ, relationships between problems and their solution patterns are organized by linking these Inventive Principles to the corresponding cells (marked " $\mathrm{X}$ " in this case) in the Contradiction Matrix. Thus, if we describe our problem to solve as a contradiction between two features, we can retrieve Inventive Principles as possible solution hints from the corresponding cell in Contradiction Matrix.

\subsection{Limitation of features in completeness}

Although 39 features have been well elaborated, completeness of the features to cover problems and contradictions about all physical phenomena such as mechanics, thermodynamics, electromagnetics, optics and acoustics, which should be described using units and quantities in Table 2, is not certain. Mann (2002b) explains that "The classical TRIZ Contradiction Matrix was assembled from primarily mechanically biased patents from twenty or more years ago" and reports relative efficacy of Contradiction Matrix for different problem types as approximately "simple mechanical" (80\%), "complex mechanical/ simple electrical" (60\%), "complex electrical" (40\%), "biomimetic" (20\%) and "management issue" (10\%). Although the number of features has been expanded from 39 to 48, and then to 50 as in Table 1(b) (Mann, 2009) and a computer tool to support these three versions of Contradiction Matrix is reported (Ang et al., 2013), essential limitation still seems to remain.

\subsection{Limitation of contradiction matrix in searchability}

Since Contradiction Matrix is rigidly classified and structured based on features, an existing relevant contradiction may not be properly searched if an essentially same problems are described differently. For example, if a problem to search is described as "a portable pointing rod of long length to use and short length to carry", the search is done about the cell marked "?" in Figure 1(a) and the existing answer in the cell marked " $X$ " might be missed. Although some studies propose introducing "ontology" to improve TRIZ (Cavallucci et al., 2011) (Prickett and Aparicio, 2012), such word-based approach may not completely solve the above-mentioned limitations.

\section{PROPOSAL OF USING QUANTITY IN SI UNIT AS FEATURE}

\subsection{Quantity in SI unit as feature}

To solve the limitation described in 2.2, the author proposes to use quantities in SI unit (SI, 2014) to describe contradictions. Effectiveness of physical quantity approach to knowledge management has been reported in some studies (Gruber and Olsen, 1994) (Hiraoka et al., 2016). In SI, all physical 
Table 2. Examples of unit and quantity in SI

(a) Space, time and periodic phenomena

\begin{tabular}{|c|l|}
\hline Unit & \multicolumn{1}{|c|}{ Quantity } \\
\hline $\mathrm{Hz}$ & frequency \\
\hline $\mathrm{m} / \mathrm{s}$ & velocity \\
\hline
\end{tabular}

\begin{tabular}{|c|l|}
\hline Unit & \multicolumn{1}{|c|}{ Quantity } \\
\hline $\mathrm{m} / \mathrm{s}^{2}$ & acceleration \\
\hline $\mathrm{rad}$ & plane angle \\
\hline
\end{tabular}

\begin{tabular}{|c|l|}
\hline Unit & \multicolumn{1}{|c|}{ Quantity } \\
\hline $\mathrm{rad} / \mathrm{s}$ & angular velocity \\
\hline $\mathrm{sr}$ & solid angle \\
\hline
\end{tabular}

(b) Mechanics

\begin{tabular}{|c|l|}
\hline$\left(\mathrm{m}^{2}\right) / \mathrm{s}$ & kinematic viscosity \\
\hline $\mathrm{kg}^{*}(\mathrm{~m} / \mathrm{s})$ & momentum \\
\hline $\mathrm{kg}^{*}(\mathrm{~m} / \mathrm{s})^{*} \mathrm{~m}$ & moment of momentum \\
\hline $\mathrm{kg}^{*} \mathrm{~m}^{2}$ & moment of inertia \\
\hline
\end{tabular}

\begin{tabular}{|c|l|}
\hline $\mathrm{kg} / \mathrm{m}$ & linear density \\
\hline $\mathrm{kg} / \mathrm{m}^{3}$ & density \\
\hline $\mathrm{kg} / \mathrm{s}$ & mass flow rate \\
\hline $\mathrm{m}^{3} / \mathrm{s}$ & $\begin{array}{l}\text { volume flow } \\
\text { rate }\end{array}$ \\
\hline
\end{tabular}

\begin{tabular}{|c|l|}
\hline $\mathrm{N}^{*} \mathrm{~m}$ & moment of force \\
\hline $\mathrm{N} / \mathrm{m}$ & surface tension \\
\hline $\mathrm{Pa}$ & pressure, stress \\
\hline $\mathrm{Pa}^{*} \mathrm{~s}$ & viscosity \\
\hline
\end{tabular}

(c) Heat

\begin{tabular}{|c|c|c|c|}
\hline $\mathrm{J} / \mathrm{K}$ & heat capacity, entropy & $\mathrm{K}^{-1}$ & linear expansion coefficient \\
\hline $\mathrm{J} / \mathrm{kg}$ & specific enthalpy, specific latent heat & $\mathrm{W}$ & heat flow rate \\
\hline $\mathrm{J} /(\mathrm{kg} * \mathrm{~K})$ & specific heat capacity, specific entropy & $\mathrm{W} /(\mathrm{m} * \mathrm{~K})$ & thermal conductivity \\
\hline $\mathrm{K} / \mathrm{W}$ & thermal resistance & $\mathrm{W} /\left(\mathrm{m}^{2} * \mathrm{~K}\right)$ & coefficient of heat transfer \\
\hline
\end{tabular}

(d) Electrical and magnetic

\begin{tabular}{|c|c|c|c|c|c|}
\hline $\mathrm{A}^{*} \mathrm{~m}^{2}$ & magnetic moment & \multirow[t]{2}{*}{$\mathrm{C} / \mathrm{m}^{3}$} & \multirow{2}{*}{$\begin{array}{l}\text { volume density of } \\
\text { charge }\end{array}$} & Ohm*m & resistivity \\
\hline \multirow{2}{*}{$\mathrm{A} / \mathrm{m}$} & \multirow{2}{*}{$\begin{array}{l}\text { linear current } \\
\text { density }\end{array}$} & & & $\mathrm{S} / \mathrm{m}$ & conductivity \\
\hline & & $\mathrm{F} / \mathrm{m}$ & permittivity & $\mathrm{V}^{*} \mathrm{~A}$ & apparent power \\
\hline $\mathrm{A} / \mathrm{m}^{2}$ & current density & $\mathrm{H} / \mathrm{m}$ & permeability & $\mathrm{V} / \mathrm{m}$ & electric field strength \\
\hline $\mathrm{C}$ & electric charge & $\mathrm{H}^{-1}$ & reluctance & $\mathrm{Wb}$ & magnetic flux \\
\hline
\end{tabular}

(e) Optics and related electromagnetic radiation

\begin{tabular}{|c|l|}
\hline$(\mathrm{m} / \mathrm{s}) /(\mathrm{m} / \mathrm{s})$ & refractive index \\
\hline $\mathrm{cd} / \mathrm{m}^{2}$ & luminance \\
\hline $\mathrm{lm}$ & luminous flux \\
\hline
\end{tabular}

\begin{tabular}{|c|l|}
\hline $1 \mathrm{~m} * \mathrm{~s}$ & quantity of light \\
\hline $1 \mathrm{~m} / \mathrm{m}^{2}$ & luminous exitance \\
\hline $\mathrm{lm} / \mathrm{W}$ & luminous efficacy \\
\hline
\end{tabular}

\begin{tabular}{|c|l|}
\hline $1 \mathrm{x}$ & illuminance \\
\hline $1 \mathrm{x}^{*} \mathrm{~s}$ & light exposure \\
\hline $\mathrm{W} / \mathrm{sr}$ & radiant intensity \\
\hline
\end{tabular}

\begin{tabular}{|c|l|}
\hline $\mathrm{dB}$ & sound pressure level \\
\hline $\mathrm{m}^{3} / \mathrm{s}$ & volume flow rate \\
\hline $\mathrm{N} * \mathrm{~s} / \mathrm{m}$ & mechanical impedance \\
\hline
\end{tabular}

(f) Acoustics

\begin{tabular}{|c|c|c|c|}
\hline $\mathrm{Pa}{ }^{*} \mathrm{~s} / \mathrm{m}$ & $\begin{array}{l}\text { specific acoustic } \\
\text { impedance }\end{array}$ & W & $\begin{array}{l}\text { sound energy } \\
\text { flux }\end{array}$ \\
\hline $\mathrm{Pa} * \mathrm{~s} / \mathrm{m}^{3}$ & acoustic impedance & $\mathrm{W} / \mathrm{m}^{2}$ & sound intensity \\
\hline
\end{tabular}

(g) Physical chemistry and molecular physics

\begin{tabular}{|c|l|}
\hline $\mathrm{J} / \mathrm{mol}$ & molar internal energy \\
\hline $\mathrm{J} /(\mathrm{mol} * \mathrm{~K})$ & molar heat capacity, molar entropy \\
\hline $\mathrm{kg} / \mathrm{mol}$ & molar mass \\
\hline
\end{tabular}$\quad$\begin{tabular}{|c|l|}
\hline $\mathrm{m}^{3} / \mathrm{mol}$ & molar volume \\
\hline $\mathrm{mol} / \mathrm{kg}$ & molality of solute substance \\
\hline $\mathrm{mol} / \mathrm{m}^{3}$ & concentration of substance \\
\hline
\end{tabular}

(h) lonizing radiation

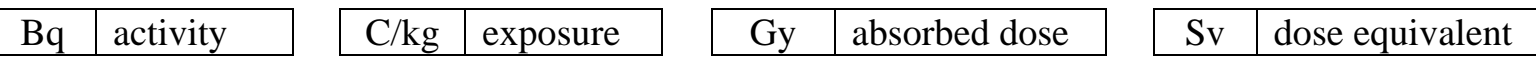

quantities describing physical phenomena can be defined by a combination of seven base quantities (and their units): length $(\mathrm{m})$, mass $(\mathrm{kg})$, time (s), electric current $(\mathrm{A})$, thermodynamic temperature $(\mathrm{K})$, amount of substance (mol) and luminous intensity (cd). Because of the generality of SI, we can expect that quantities in SI can describe all possible contradictions about physical phenomena.

\subsection{Dimensional similarity between quantities}

Another merit of using quantities in SI is introductions of not only an exact match but also partial match between features based on dimensional analysis of quantities so that we can estimate some relevance between two contradictions "long length to use and small volume to carry" and "long length to use and short length to carry". In this research, the author defines dimensional similarity between quantities as an ordinal scale as follows (greater number means higher similarity). Table 3 summarizes the similarity definition and Table 4 shows examples of similarity between two quantities. 
- $\quad$ DEF_EQ (7): Both dimension and expression are same.

- DIM_EQ (6): Dimension is same but expressions are different.

- DIMLESS_SIM (5): Similarity between dimensional quantity and its nondimensionalization.

- $\quad$ M_S_SIM1 (4), M_S_SIM2 (3), M_S_SIM3 (2): Among seven base quantities, length and time are considered specially. Some similarity is given between a dimensional quantity and that per length, per area and per volume, or its velocity, acceleration and jerk.

- NO_SIM (1): No similarity is given.

\subsection{Qualitative value of quantity and its similarity}

To describe a contradiction between quantities, this research introduce qualitative values as in qualitative physics (Bhaskar and Nigam 1990) as follows.

- $\quad+$ : The magnitude of the quantity is high, big, long, more, increase.

- $\quad$ 0: (Currently not used.)

- $\quad$-: The magnitude of the quantity is low, small, short, less, decrease.

By using this qualitative value, two contradictions "long length to use and small volume to carry" and "long length to use and short length to carry" are indexed as (m:+, $\left.\mathrm{m}^{3}:-\right)$ and (m:+, m:-), respectively. Here we define similarity between qualitative values as in Table 5 . As the result, dimensional similarity and value similarity are calculated as DEF_EQ:EQ between m:+ and m:+, and M_S_SIM2:EQ between $\mathrm{m}^{3}$ :- and $\mathrm{m}:-$.

Table 3. Definition of dimensional similarity between quantities.

\begin{tabular}{|c|c|c|c|c|c|c|c|}
\hline \multirow{3}{*}{\multicolumn{2}{|c|}{$\operatorname{sim}\left(\operatorname{dim}_{1}, \operatorname{dim}_{2}\right)$}} & \multicolumn{6}{|c|}{ Dimension $\boldsymbol{d i m}_{2}$} \\
\hline & & \multirow{2}{*}{\multicolumn{4}{|c|}{ Dimensional }} & \multicolumn{2}{|c|}{ Dimensionless } \\
\hline & & & & & & $\operatorname{dim}_{2}=\operatorname{dim}_{1} / \operatorname{dim}_{1}$ & Otherwise \\
\hline \multirow{8}{*}{$\begin{array}{l}\text { Dimension } \\
\boldsymbol{d i m}_{1}\end{array}$} & \multirow{6}{*}{ Dimensional } & \multirow{2}{*}{$\begin{array}{c}\operatorname{dim}_{1}= \\
\operatorname{dim}_{2}\end{array}$} & \multirow{2}{*}{\multicolumn{2}{|c|}{$\begin{array}{l}\text { Definitions match } \\
\text { Definitions differ }\end{array}$}} & DEF_EQ (7) & \multirow{6}{*}{ DIMLESS_SIM (5) } & \multirow{6}{*}{ NO_SIM (1) } \\
\hline & & & & & DIM_EQ (6) & & \\
\hline & & \multirow{4}{*}{$\begin{array}{c}\operatorname{dim}_{1} \neq \\
\operatorname{dim}_{2}\end{array}$} & \multirow{3}{*}{$\begin{array}{c}\operatorname{dim}_{1}= \\
\operatorname{dim}_{2} * \mathrm{~m}^{k} \\
\text { or } \\
\operatorname{dim}_{2} * \mathrm{~s}^{k}\end{array}$} & $k= \pm 1$ & M_S_SIM1 (4) & & \\
\hline & & & & \pm 2 & M_S_SIM2 (3) & & \\
\hline & & & & \pm 3 & M_S_SIM3 (2) & & \\
\hline & & & \multicolumn{2}{|c|}{ Otherwise } & NO_SIM (1) & & \\
\hline & \multirow{2}{*}{ Dimensionless } & \multicolumn{3}{|c|}{$\operatorname{dim}_{1}=\operatorname{dim}_{2} / \operatorname{dim}_{2}$} & DIMLESS_SIM (5) & DEF_EQ (7) & \multirow[b]{2}{*}{ DIM EQ (6) } \\
\hline & & \multicolumn{3}{|c|}{ Otherwise } & NO_SIM (1) & & \\
\hline
\end{tabular}

Table 4. Examples of dimensional similarity between quantities.

\begin{tabular}{|c|c|c|}
\hline Quantity, unit expression, dimension* & Quantity, unit expression, dimension* & Similarity \\
\hline Work, $\mathrm{N}^{*} \mathrm{~m},[2,1,-2,0,0,0,0]$ & Work, $\mathrm{N}^{*} \mathrm{~m},[2,1,-2,0,0,0,0]$ & DEF_EQ \\
\hline Strain, $\mathrm{m} / \mathrm{m},[0,0,0,0,0,0,0]$ & Strain, $\mathrm{m} / \mathrm{m},[0,0,0,0,0,0,0]$ & DEF_EQ \\
\hline Work, $\mathrm{N}^{*} \mathrm{~m},[2,1,-2,0,0,0,0]$ & $\begin{array}{l}\text { Kinetic energy, } \mathrm{kg} *(\mathrm{~m} / \mathrm{s})^{2} \\
{[2,1,-2,0,0,0,0]}\end{array}$ & DIM_EQ \\
\hline Strain, $\mathrm{m} / \mathrm{m},[0,0,0,0,0,0,0]$ & $\begin{array}{l}\text { Energy efficiency, } \mathrm{J} / \mathrm{J} \\
{[0,0,0,0,0,0,0]}\end{array}$ & DIM_EQ \\
\hline $\begin{array}{l}\text { Dimensionless quantity**, } \\
{[0,0,0,0,0,0,0]}\end{array}$ & Strain, $\mathrm{m} / \mathrm{m},[0,0,0,0,0,0,0]$ & DIM_EQ \\
\hline $\begin{array}{l}\text { Energy efficiency, } \mathrm{J} / \mathrm{J} \\
{[0,0,0,0,0,0,0]}\end{array}$ & Energy, $\mathrm{J},[2,1,-2,0,0,0,0]$ & DIMLESS_SIM \\
\hline Power, W, $[2,1,-3,0,0,0,0]$ & Energy, J, $[2,1,-2,0,0,0,0]$ & M_S_SIM1 \\
\hline Stress, Pa, $[-1,1,-2,0,0,0,0]$ & Force, $\mathrm{N},[1,1,-2,0,0,0,0]$ & M_S_SIM2 \\
\hline Mass, kg, $[0,1,0,0,0,0,0]$ & Density, $\mathrm{kg} / \mathrm{m}^{3},[-3,1,0,0,0,0,0]$ & M_S_SIM3 \\
\hline $\begin{array}{l}\text { Molar concentration, } \mathrm{mol} / \mathrm{m}^{3} \text {, } \\
{[-3,0,0,0,0,1,0]}\end{array}$ & $\begin{array}{l}\text { Electric potential difference, } \mathrm{V}, \\
{[2,1,-3,-1,0,0,0]}\end{array}$ & NO_SIM \\
\hline
\end{tabular}

* Dimension represents exponents of seven SI base quantities.

** This research introduces an original unit symbol "_" for dimensionless quantity such as number of items for convenience. 
Table 5. Definition of similarity between qualitative values

\begin{tabular}{|c|c|c|c|c|}
\hline \multirow{2}{*}{$\operatorname{sim}$} & \multicolumn{3}{|c|}{$v a l_{2}$} \\
\cline { 3 - 5 } & - & 0 & + \\
\hline \multirow{3}{*}{$v a l_{1}$} & - & EQ & ZNZ & INV \\
\cline { 2 - 5 } & 0 & ZNZ & EQ & ZNZ \\
\cline { 2 - 5 } & + & INV & ZNZ & EQ \\
\hline
\end{tabular}

EQ: Equal

ZNZ: Zero and non-zero

INV: Inverse

$\mathrm{EQ}>\mathrm{ZNZ}>\mathrm{INV}$

\section{PROPOSAL OF SEMISTRUCTURED CONTRADICTION MATRIX BASED ON PHYSICAL QUANTITY}

Now that a contradiction is described by not prefixed 39 features but any quantities in SI unit, a contradiction matrix in this research does not have fixed number of rows and columns. Thus, this research proposes a semistructured (Feldman and Sanger, 2007) contradiction matrix based on physical quantity as illustrated in Figure 1(b). This semistructured contradiction matrix is a database containing matrix items each of which consist of a contradiction to solve and solution examples for it. Currently the author stores 27 matrix items some of which are shown in Table 6 where only No. 1 is described in the exact XML syntax using the following tags and attributes: "<contradict>": tag for a contradiction, "unit\#": attribute for unit expression of feature \# (1 or 2) to form the contradiction, "qval\#": attribute for qualitative value of feature \# to form the contradiction, "<eng >": tag for English description (of a contradiction and a solution), "<f\#>": tag for word or phrase of the name of feature \#, "<v\#>": tag for word or phrase of the qualitative value of feature \#, "<solutions>": tag for solutions, "<sol>": tag for a solution, and "num": attribute for the number of TRIZ Inventive Principles for the solution.

As described by "unit\#" and "qval\#" attributes in a "contradiction" tag in No.1 of Table 6, a contradiction is summarized by quantity units and qualitative values of the two features, and we call them a contradiction index. For example, a contradiction index for the matrix item No.1 in Table 6 is noted as (unit1="m" qual1="+" unit2="m 3 " qval2="-").

In this research, a typical usage of a semistructured contradiction matrix for knowledge management for problem solving should be as follows (Figure 2).

1. A designer describes a contradiction to solve as a retrieval key and notes it as a contradiction index by quantity units and qualitative values.

2. A system calculates similarities between the key contradiction index and every contradiction index of all matrix items stored in the semistructured contradiction matrix.

3. A system sorts the matrix items in the semistructured contradiction matrix in the order of high index similarity with the key index and presents them to the designer.

4. The designer may obtain hints to solve the key contradiction by referring to the relevant contradictions and the solutions and their TRIZ Inventive Principles linked to the contradictions.

Describing contradictions by not TRIZ 39 features but physical quantities should lead to the following advantages.

- $\quad$ Since contradictions can be described by any physical quantities in SI units, we should be able to avoid possible incompleteness of TRIZ 39 features as described in 2.2.

- Matrix items stored in the semistructured contradiction matrix can be searched and presented in the order of high similarity to the retrieval key contradiction. Therefore, we can find not only contradictions with exactly same contradiction index to the retrieval key (exact match) but also contradictions with similar or relevant contradiction index to the retrieval key (partial match) as depicted in Figure 1(b). This capability should enable us to avoid limitation in searchability of TRIZ Contradiction Matrix as described in 2.3

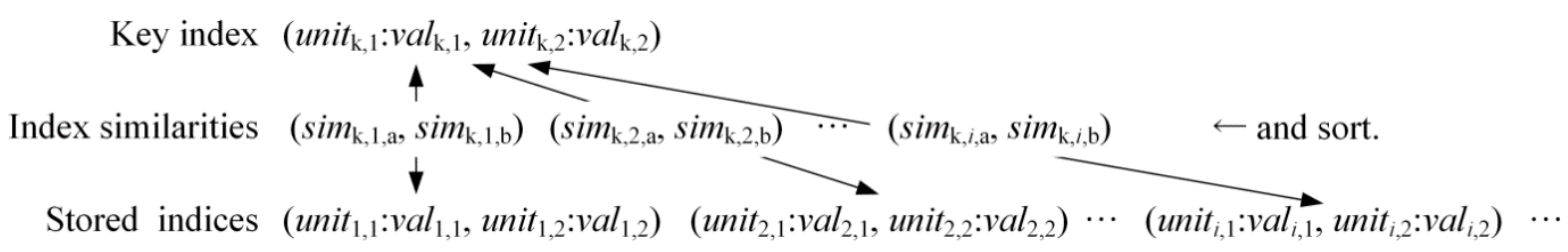

Figure 2. Search for similar contradictions from semistructured contradiction matrix 
Table 6. Description of item in semistructured contradiction matrix

\begin{tabular}{|c|c|}
\hline No. & Item content in semistructured contradiction matrix \\
\hline 1 & 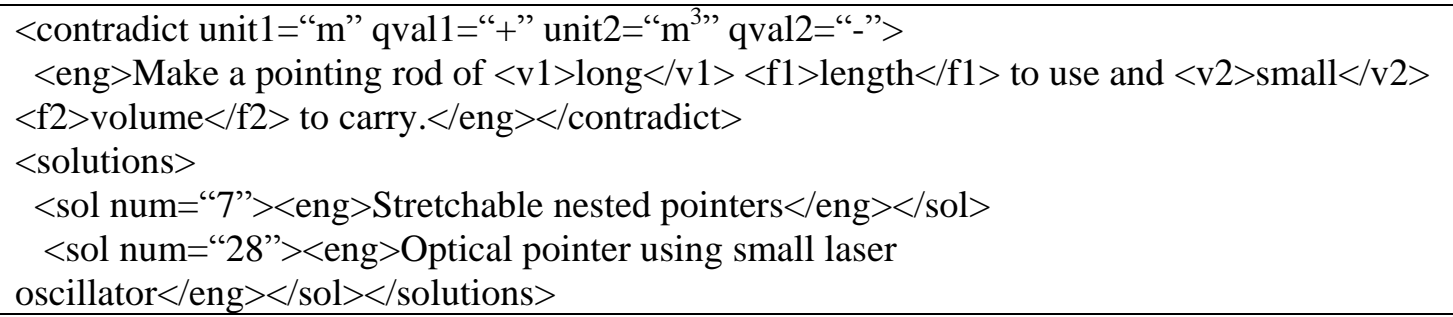 \\
\hline 2 & $\begin{array}{l}\text { Contradiction: "Solar panel of an artificial satellite whose volume at launch is small but the } \\
\text { area in use is large." (unit1="“m" qval1="-" unit2=" } \mathrm{m}^{2 "} \text { qval2="+"”) } \\
\text { Solution }(15,17) \text { : "Folding structure" }\end{array}$ \\
\hline 3 & $\begin{array}{l}\text { Contradiction: "Make a beach ball of large volume to play and small volume to carry." } \\
\text { (unit } 1=" \mathrm{~m}^{3 \text { " }} \text { qval1="-" unit } 2=" \mathrm{~m}^{33} \text { " qval2="+") } \\
\text { Solution }(15,17,29) \text { : "Inflate the beach ball with air to use and pull air out to carry." }\end{array}$ \\
\hline 4 & $\begin{array}{l}\text { Contradiction: "Make a mosquito incense with a small installation volume and a long } \\
\text { burning time." (unit1="" } \mathrm{m}^{3 \text { " }} \text { qval1="-" unit2="s" qval2="++") } \\
\text { Solution (17): "Make it spiral and burn." }\end{array}$ \\
\hline 5 & $\begin{array}{l}\text { Contradiction: "Walk a long distance in a small area." (unit1=" }{ }^{2 " ”} \text { qval1=“"-" unit2=“"m" } \\
\text { qval2="“+") } \\
\text { Solution (20): "Treadmill" }\end{array}$ \\
\hline 6 & $\begin{array}{l}\text { Contradiction: "In radiotherapy, makes the irradiation to the affected part high and the } \\
\text { irradiation to other parts low." (unit } 1=\text { "Gy" qval1="+" unit } 2=\text { "Gy" qval2="-") } \\
\text { Solution (1): "Stereotactic irradiation, in which radiation is split and focused only on the } \\
\text { affected part." }\end{array}$ \\
\hline 7 & $\begin{array}{l}\text { Contradiction: "Make a high rigidity PET bottle with a small amount of material." } \\
\text { (unit1="kg" qval1="-" unit2="N/m" qval2="+") } \\
\text { Solution (29): "Support the shape of PET bottle with internal pressure of carbonated } \\
\text { beverage." }\end{array}$ \\
\hline 8 & $\begin{array}{l}\text { Contradiction: "Mount a large number of elements on a small area." (unit } 1=" \mathrm{~m}^{2, "} \text { qval1=“-” } \\
\text { unit2="_" qval2=“++") } \\
\text { Solution (17): "Multi-layer substrate" }\end{array}$ \\
\hline 9 & $\begin{array}{l}\text { Contradiction: "Sharks swim at a fast speed with little effort." (unit1="W" qval1="-" } \\
\text { unit2="m/s" qval2="++") } \\
\text { Solution }(3,17) \text { : "Fine protrusions on the skin surface reduce the resistance of water." }\end{array}$ \\
\hline 10 & $\begin{array}{l}\text { Contradiction: "Make a stapler of small size with a long arm length for saddle stitch." } \\
\quad \text { (unit } 1=\text { " } \mathrm{m}^{3 \text { " }} \text { qvall="-"” unit } 2=\text { " } \mathrm{m} \text { " qval2=“+") } \\
\text { Solution }(6,15) \text { : "The structure of a rotatable magazine to staple the needle in a deep } \\
\text { position." }\end{array}$ \\
\hline 11 & $\begin{array}{l}\text { Contradiction: "Make a flywheel of small diameter and great moment of inertia." (unit } 1=\text { "m" } \\
\text { qval1="-" unit } 2=\text { " } \mathrm{kg}^{*} \mathrm{~m}^{2, "} \text { qval2=“+") } \\
\text { Solution (3): "Concentrate the mass around the perimeter." }\end{array}$ \\
\hline 12 & $\begin{array}{l}\text { Contradiction: "Increase the air volume of the air cooling fan but reduce the noise." } \\
\text { (unit } 1=\text { " } \mathrm{m}^{3} / \mathrm{s} \text { " qval } 1=\text { " }+" \text { unit } 2=\text { "dB" qval2="-") } \\
\text { Solution (29): "Use water cooling instead of air cooling." }\end{array}$ \\
\hline
\end{tabular}

Calculation of similarity between contradiction indices is detailed in the Appendix.

There is a study (Robles et al., 2009) that stores problem solving cases (contradictions and associated principles) in Contradictions Memory, not Contradiction Matrix, and retrieve similar cases from it. Their method is different from this research because they describe contradictions by TRIZ features.

\section{FICTIVE EXAMPLE OF IDEA SEARCH}

To confirm efficacy of exact-match and partial-match in this research, the proposed method is implemented as a software in Python 3. Currently 27 matrix items are described as shown in Table 6 
and stored in the semistructured contradiction matrix. Using the software and the semistructured contradiction matrix, the author searches ideas for "a stick of long length to use and short length to carry" whose contradiction index is (unit $1=$ "m" qval1="+" unit $2=$ "m" qval2="-") as a fictive example. The software calculates similarity between the contradiction index of the search key and that of each matrix item, and displays the searched results in the order of higher similarity. Figure 3(a) shows a snapshot of the actual software and Figure 3(b) lists the five searched results (calculated similarity as in 3.2 and 3.3, text and index of the contradiction).

Table 7 is a part of TRIZ Contradiction Matrix cells. If we use Contradiction Matrix, only cells surrounded by thick lines are searched because the contradiction of the search key is length vs. length. In this research, however, cells with "*”" are also obtained as partially-matched contradictions. From the solution examples associated with the searched contradictions as shown in Table 6, we should obtain ideas such as a stretchable nested structure, a folding structure and an inflation structure for the stick. These results indicates that partial match introduced by this research in searching for related contradictions should enhance capability of a contradiction matrix as a framework for knowledge management for problem solving.

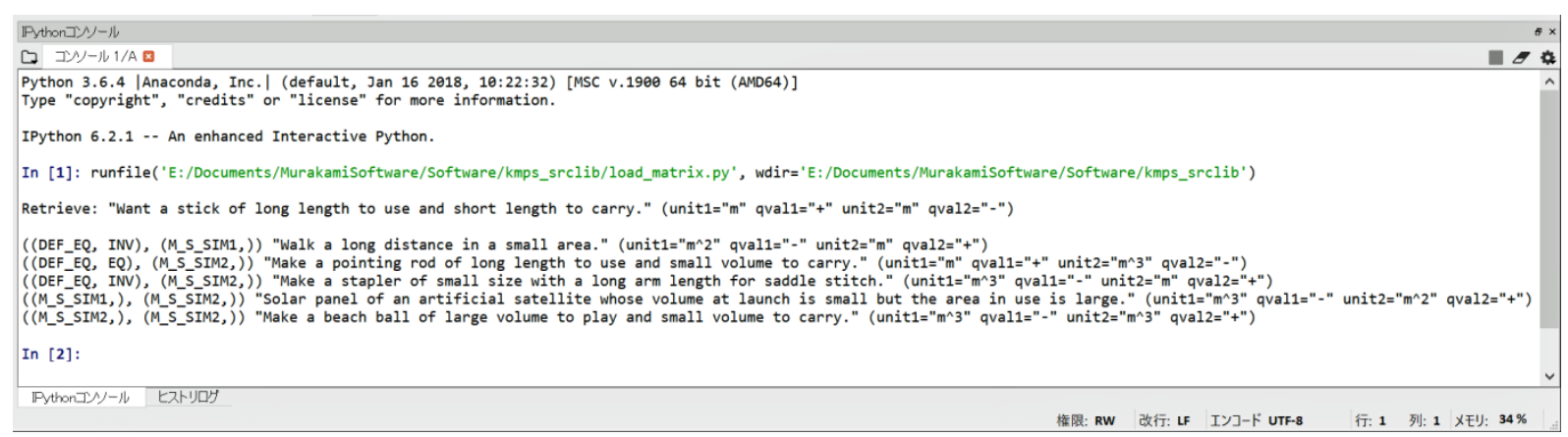

(a) Snapshot of the software

Retrieve: "Want a stick of long length to use and short length to carry." (unit1="m" qval1="+" unit2="m" qval2="-")

((DEF_EQ, INV), (M_S_SIM1,)) "Walk a long distance in a small area." (unit1=“m²" qval1=“_-" unit2="m" qval2="+")

((DEF_EQ, EQ), (M_S_SIM2,)) "Make a pointing rod of long length to use and small volume to carry." (unit1="m" qval1="“+" unit2="“m "3" qval2="-")

((DEF_EQ, INV), (M_S_SIM2,)) "Make a stapler of small size with a long arm length for saddle stitch." (unit1="m" ${ }^{3, "}$ qval1="-" unit2="m" qval2="“+")

((M_S_SIM1,), (M_S_SIM2,)) "Solar panel of an artificial satellite whose volume at launch is small but the area in use is large." (unit1=""m 3" qval1="-" unit2="m" qval2="+")

((M_S_SIM2,), (M_S_SIM2,)) "Make a beach ball of large volume to play and small volume to

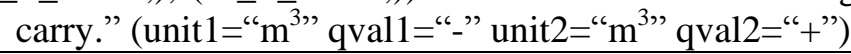

(b) Retrieval result

Figure 3. Fictive example of idea search

Table 7. Comparison of search results in TRIZ Contradiction Matrix

\begin{tabular}{|l|l|l|l|}
\hline & 3, 4. Length & 5, 6. Area & 7, 8. Volume \\
\hline 3, 4. Length of object & & $* 20$ & $* 6,7,15,28$ \\
\hline 5, 6. Area of object & $* 20$ & & $* 15,17$ \\
\hline 7, 8. Volume of object & $* 6,7,15,28$ & $* 15,17$ & $* 15,17,29$ \\
\hline
\end{tabular}

\section{CONCLUSIONS}

- Possible limitation of TRIZ 39 features in completeness to cover various physical phenomena is pointed out and using physical quantities for contradiction descriptions is proposed.

- Possible limitation of rigidly classified TRIZ Contradiction Matrix in searchability is pointed out and semistructured contradiction matrix based on physical quantity contradictions is proposed.

- To enable not only exact match but also partial match in searching for relevant contradictions in a semistructured contradiction matrix, dimensional similarity and qualitative value similarity of physical quantity and similarity between contradictions are defined. 
- The proposed method is implemented as software in Python, and contradictions and their solutions are described in XML and stored in a semistructured contradiction matrix.

- From the result of similarity calculation between stored contradictions, possible effectiveness of the proposed method of knowledge management for problem solving is confirmed.

\section{REFERENCES}

Ang, M.C., Ng, K.W., Ahmad, S.A. and Wahab, A.N.A. (2013), “An Engineering Design Support Tool Based on TRIZ", Third International Visual Informatics Conference, IVIC 2013, Selangor, Malaysia, November 13-15, pp. 115-127.

Bhaskar, R. and Nigam, A. (1990), "Qualitative Physics Using Dimensional Analysis", Artificial Intelligence, Vol. 45 No. 1-2, pp. 73-111, http://doi.org/10.1016/0004-3702(90)90038-2.

Bureau International des Poids et Mesures. (2014), SI brochure, 8th ed. (update), pp. 111-120.

Cavallucci, D., Rousselot, F. and Zanni, C. (2011), "An Ontology for TRIZ”, Procedia Engineering, Vol. 9, pp.251-260, http://doi.org/10.1016/j.proeng.2011.03.116.

Feldman, R. and Sanger, J. (2007), The Text Mining Handbook: Advanced Approaches in Analyzing Unstructured Data, Cambridge University Press, New York, pp.3-4.

Gruber, T.R. and Olsen, G.R. (1994), “An Ontology for Engineering Mathematics”, Fourth International Conference on Principles of Knowledge Representation and Reasoning, Bonn, Germany, pp. 1-18.

Hiraoka, Y., Murakami, T., Yamamoto, K., Furukawa, Y. and Sawada, H. (2016), "Method of Computer-Aided Fault Tree Analysis for High-Reliable and Safety Design", IEEE Transactions on Reliability, Vol. 65 No.2, pp. 687-703, http://doi.org/10.1109/TR.2015.2513050.

Ilevbare, I.M., Probert, D. and Phaal, R. (2013), "A Review of TRIZ, and Its Benefits and Challenges in Practice", Technovation, Vol. 33, pp. 30-37, http://doi.org/10.1016/j.technovation.2012.11.003.

Mann, D. (2001), “An Introduction to TRIZ: The Theory of Inventive Problem Solving”, Creativity and Innovation Management, Vol. 10 No. 2, pp. 123-125.

Mann, D. (2002a), Hands-On Systematic Innovation, CREAX Press, Belgium (Japanese translation).

Mann, D. (2002b), "Assessing the Accuracy of the Contradiction Matrix for Recent Mechanical Inventions", TRIZ Journal, pp. 1-9.

Mann, D. (2009), Matrix 2010: Re-updating the TRIZ Contradiction Matrix, IFR Press (Japanese translation).

Prickett, P. and Aparicio, I. (2012), "The development of a modified TRIZ Technical System ontology", Computers in Industry, Vol. 63, pp. 252-264, http://doi.org/10.1016/j.compind.2012.01.006.

Robles, G.C., Negny, S. and Lann, J.M.L. (2009), "Case-based Reasoning and TRIZ: A Coupling for Innovative Conception in Chemical Engineering", Chemical Engineering and Processing: Process Intensification, Vol. 48 No. 1, pp. 239-249, http://doi.org/10.1016/j.cep.2008.03.016.

\section{APPENDIX}

\section{A.1 Similarity between two contradictions}

In this research, a physical quantity is represented as unit:val where unit is a unit expression (e.g., $\mathrm{kg} * \mathrm{~m} / \mathrm{s}^{2}$ ) and $v a l$ is a qualitative value (i.e.,,- 0 , or + ) of the quantity. Since a contradiction is typically described as a conflict between two quantities, a contradiction ${ }_{i}$ can be indexed as unit $_{i, 1}:$ val $_{i, 1}$, unit $t_{i, 2}$ : $v a l_{i, 2}$ ) for the conflicting quantity 1 and quantity 2 at (I) and (II) in Figure A.1.

Here we define a similarity between contradiction ${ }_{i}$ and contradiction $_{j}$ by a similarity between their

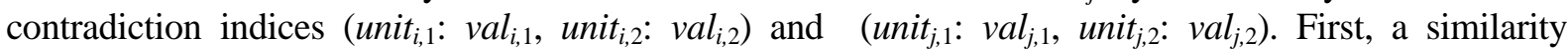
between two quantities is defined as $\operatorname{sim}_{\mathrm{dim}}: \operatorname{sim}_{\mathrm{val}}$ where $\operatorname{sim}_{\mathrm{dim}}$ is a dimensional similarity (DEF_EQ, DIM_EQ, DIMLESS_SIM, M_S_SIM1, M_S_SIM2, M_S_SIM3, or NO_SIM) and $\operatorname{sim}_{\text {val }}$ is a qualitative value similarity (EQ, ZNZ, or INV) as defined in 3.2 and 3.3. Although contradiction index similarity can be defined as similarity between a quantity set and the other quantity set, two ways of pairing, i.e., parallel pairing and cross pairing, should be considered as (III) in Figure A.1 because the description order of two quantities in a contradiction may not be consistent. Then the two contradiction index similarity candidates at (III) in Figure A.1 are compared in the way described in A.2 and greater one is determined as the similarity between two contradictions $i$ and $j$ as (IV) and (V) in Figure A.1.

\section{A.2 Comparison of two contradiction similarities}

To sort contradictions stored in a semistructured contradiction matrix in the order of higher similarity with the key contradiction in Figure 2, we need to compare two contradiction similarities. Suppose we compare two contradiction index similarities $\left(\operatorname{sim}_{i, \mathrm{a}}, \operatorname{sim}_{i, \mathrm{~b}}\right)$ and $\left(\operatorname{sim}_{\mathrm{j}, \mathrm{a}}, \operatorname{sim}_{j, \mathrm{~b}}\right)$ as defined in A.1, where $\operatorname{sim}_{i, \mathrm{a}}, \operatorname{sim}_{i, \mathrm{~b}}$, 
$\operatorname{sim}_{j, \mathrm{a}}, \operatorname{sim}_{j, \mathrm{~b}}$ are quantity similarities. Here we assume $\operatorname{sim}_{i, \mathrm{a}}>=\operatorname{sim}_{i, \mathrm{~b}}$ and $\operatorname{sim}_{j, \mathrm{a}}>=\operatorname{sim}_{\mathrm{j}, \mathrm{b}}$, which does not lose generality. First, we compare $\operatorname{sim}_{i, \mathrm{a}}$ and $\operatorname{sim}_{j, \mathrm{a}}$ and $\operatorname{sim}_{i, \mathrm{~b}}$ and $\operatorname{sim}_{j, \mathrm{~b}}$ respectively. Among nine possible combinations of $\left(r e l_{\mathrm{a}}, r e l_{\mathrm{b}}\right)$ in Table A.1, $(<,<),(<,=)$ and $(=,<)$ determine the total relationship rel between $\left(\operatorname{sim}_{i, \mathrm{a}}, \operatorname{sim}_{i, \mathrm{~b}}\right)$ and $\left(\operatorname{sim}_{j, \mathrm{a}}, \operatorname{sim}_{j, \mathrm{~b}}\right)$ as $<,(=,=)$ determines $\mathrm{rel}$ as =, and $(=,>),(>,=)$ and $(>,>)$ determine $r e l$ as $>$. For $(<,>)$ and $(>,<)$, detailed check is needed. Take the combination marked with "?*" where $\operatorname{sim}_{i, \mathrm{a}}>\operatorname{sim}_{j, \mathrm{a}}$ and $\operatorname{sim}_{i, \mathrm{~b}}<\operatorname{sim}_{j, \mathrm{~b}}$ for example. In such a case, how $\operatorname{sim}_{i, \mathrm{a}}$ is greater than $\operatorname{sim}_{j, \mathrm{a}}$ and how $\operatorname{sim}_{i, \mathrm{~b}}$ is less than $\operatorname{sim}_{j, \mathrm{~b}}$ need to be totalized. For this purpose, degrees of difference between quantity similarities are defined as ordinal scale (greater value means greater difference) as in Table A.2. Although the difference is degreed by dimensional difference, qualitative value difference is also considered when the two quantity similarities are both DEF_EQ or both DIM_EQ. For example, if $\operatorname{sim}_{i, \mathrm{a}}=$ DEF_EQ, $\operatorname{sim}_{j, \mathrm{a}}=$ DIM_EQ, $\operatorname{sim}_{i, \mathrm{~b}}=$ M_S_SIM1 and $\operatorname{sim}_{j, \mathrm{~b}}=$ DIMLESS_SIM, $\operatorname{sim}_{i, \mathrm{a}}$ is greater than $\operatorname{sim}_{j, \mathrm{a}}$ by 1 and $\operatorname{sim}_{i, \mathrm{~b}}$ is less than $\operatorname{sim}_{\mathrm{j}, \mathrm{b}}$ by 5 , total relationship rel is judged as <, because degree of less is greater than degree of greater.

(I) Contradictions to calculate similarity:

contradiction $_{i}$

(II) Contradiction indices: $\left(\right.$ unit $_{i, 1}:$ val $_{i, 1}$, unit $_{i, 2}:$ val $\left._{i, 2}\right)$

(III) Two ways of similarity calculation : (parallel, cross) :

(IV) Internal sort $\left(\operatorname{sim}_{\mathrm{a}}>=\operatorname{sim}_{\mathrm{b}}\right)$ :

(V) Favorable selection:

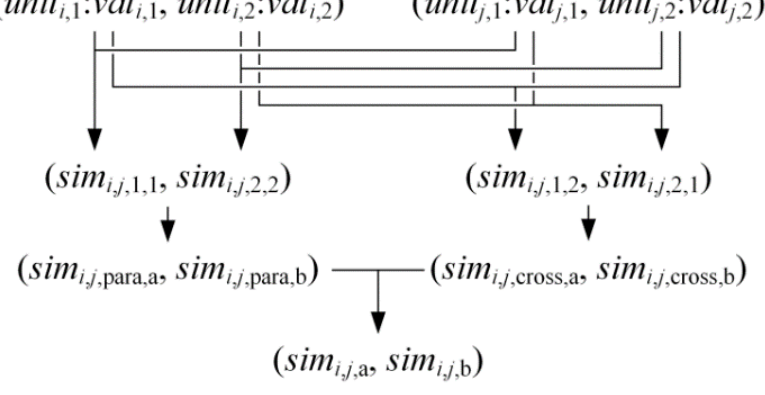

Figure A.1. Similarity calculation between two contradictions.

Table A.1. Comparing contradiction indices by comparing two quantity similarities

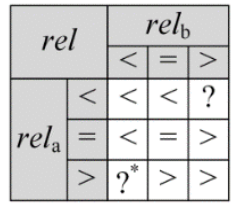

$\operatorname{sim}_{i, \mathrm{a}} \operatorname{rel}_{\mathrm{a}} \operatorname{sim}_{j, \mathrm{a}}$
$\operatorname{sim}_{i, \mathrm{~b}} \operatorname{rel}_{\mathrm{b}} \operatorname{sim}_{j, \mathrm{~b}}$
$\left(\operatorname{sim}_{i, \mathrm{a}}, \operatorname{sim}_{i, \mathrm{~b}}\right) \operatorname{rel}\left(\operatorname{sim}_{j, \mathrm{a}}, \operatorname{sim}_{j, \mathrm{~b}}\right)$

Table A.2. Definition of degree of difference between quantity similarities

\begin{tabular}{|c|c|c|}
\hline \multicolumn{2}{|c|}{ Similarity g > Similarity 1 } & $\begin{array}{c}\text { Degree of } \\
\text { difference }\end{array}$ \\
\hline DEF_EQ & NO_SIM & 21 \\
\hline DIM_EQ & NO_SIM & 20 \\
\hline DIMLESS_SIM & NO_SIM & 19 \\
\hline M_S_SIM1 & NO_SIM & 18 \\
\hline M_S_SIM2 & NO_SIM & 17 \\
\hline M_S_SIM3 & NO_SIM & 16 \\
\hline DEF_EQ & M_S_SIM3 & 15 \\
\hline DIM_EQ & M_S_SIM3 & 14 \\
\hline DEF_EQ & M_S_SIM2 & 13 \\
\hline DIM_EQ & M_S_SIM2 & 12 \\
\hline DEF_EQ & M_S_SIM1 & 11 \\
\hline DIM_EQ & M_S_SIM1 & 10 \\
\hline DEF_EQ & DIMLESS_SIM & 9 \\
\hline DIM_EQ & DIMLESS_SIM & 8 \\
\hline
\end{tabular}

\begin{tabular}{|c|c|c|}
\hline \multicolumn{2}{|c|}{ Similarity g > Similarity 1 } & $\begin{array}{c}\text { Degree of } \\
\text { difference }\end{array}$ \\
\hline DIMLESS_SIM & M_S_SIM3 & 7 \\
\hline DIMLESS_SIM & M_S_SIM2 & 6 \\
\hline DIMLESS_SIM & M_S_SIM1 & 5 \\
\hline M_S_SIM1 & M_S_SIM3 & 4 \\
\hline M_S_SIM2 & M_S_SIM3 & 3 \\
\hline M_S_SIM1 & M_S_SIM2 & 2 \\
\hline DEF_EQ & DIM_EQ & 1 \\
\hline DEF_EQ:EQ & DEF_EQ:INV & $(0,6)$ \\
\hline DEF_EQ:EQ & DEF_EQ:ZNZ & $(0,5)$ \\
\hline DEF_EQ:ZNZ & DEF_EQ:INV & $(0,4)$ \\
\hline DIM_EQ:EQ & DIM_EQ:INV & $(0,3)$ \\
\hline DIM_EQ:EQ & DIM_EQ:ZNZ & $(0,2)$ \\
\hline DIM_EQ:ZNZ & DIM_EQ:INV & $(0,1)$ \\
\hline
\end{tabular}

